\title{
On Cognitive Primitives and Trick Photography
}

\author{
Derek J. Smith \\ Cardiff Metropolitan University (retired) \\ 55 Ty-Isaf Park Road, Cardiff NP11 6NH, UK \\ smithsrisca@btinternet.com
}

\section{INTRODUCTION}

Magic shows, advertising campaigns, and political propaganda all take advantage of the fact that one's perception of a given moving image is deeply influenced by past experience and emotional state. The art of these deceptions is to tell us what we expect to see, safe in the knowledge that so much of human perception takes place subconsciously that the trickery routinely passes unnoticed. The present paper argues that the often-forgotten investigations of perceptual causality by the Belgian cognitive psychologist Albert Michotte summarised in Michotte (1963) - suggest ways in which deceitful cinematography might be forensically deconstructed.

\section{ON COGNITIVE PRIMITIVES}

The classical discussion of the nature of perception is Plato's (380BCE) Allegory of the Cave. This famous thought experiment asks you to imagine being a prisoner since birth in a dimly lit cave. All you can see are shadows cast on the wall in front of you by a fire behind your back. Moreover, these shadows are not even your own, for the fire exactly like the projection room in a cinema - has been positioned too far above your head, and the shadows are those cast by your guards as they carry various items back and forth behind you. Plato's point, of course, was that nobody ever knows the items in the world directly; rather we see only a shadow-theatre reality, and what we think we "know" is actually no more than poorly informed guesswork.

In the fullness of time Plato's philosophy of perception merged with objective neuroanatomy, complete with its notion of processing stages (retinal, subcortical, Area 17, etc.). As a result, modern visual theory routinely identifies low-level processes of data extraction, mid-level processes of attention, recognition, and emotional state, and high-level processes of conscious interpretation. What we think we see is always the result of top- level processes interpreting signals from mid-level processes, which are, in turn, always the product of signals from low-level processes. Moreover, as Meinong (1902) repeatedly demonstrated, the higher mind is perfectly capable of processing data totally invented by its mid-layer, and not factually present on the retina at all! For the remainder of this paper, the term "cognitive primitive" will be used to describe any of the mind's unconscious low- and mid-level processes. Smith's (1993) Platofriendly three-level information processing hierarchy includes a diagram that distinguishes the remoteness of AWARENESS, the ascending stages of PERCEPTION, and the multiple nested feedback circuits.

Toward the end of the 19th Century the demonstrable facts of neuroanatomy started to be complemented by equally objective results from newly established psychology laboratories at Leipzig, Würzburg, Yale, and Cambridge. This new breed of researchers quickly busied itself assessing and measuring our intellectual and workplace abilities, and fitting us more efficiently into our weapons of war. Indeed, modern cognitive psychology was only conceived with the release from war service in 1945 of hundreds of highly skilled military ergonomists. One such was the Leipzig- and Würzburg-trained experimentalist Albert Michotte. In a 30-year programme of research at the University of Leuven, Michotte deployed a simple disk-and-slot apparatus to bring visual experience under the experimental microscope. Each disk had two or three concentric coloured bands drawn onto it, such that when rotated behind a horizontal viewing slit small coloured blocks moved from side to side. In Michotte's basic study, block A moved at steady speed up to B and stopped, whereupon B moved off with zero delay. The resulting higher experience was that A had "struck" B and "launched" it, even though observers knew full well that retinally this was not the case! Readers may experience this cognitive primitive for themselves online (http://www.smithsrisca.co.uk/EVA-demo1.pptx). 
In other experiments Michotte started with a static rectangular $A$ and then created $B$ alongside it, expanding it outwards until it was the same size as A. He observed "the observer does not see the stripe form and then grow (as in reality) but rather a rigid stripe of fixed size, sliding out of the square which previously hid it" (p.127). Michotte called this cognitive primitive the screen effect, and readers may experience the phenomenon for themselves online (http://www.smithsrisca.co.uk/EVAdemo2.pptx).

In a variant of the screen effect, a long block $A$ moved up to a static block $B$, which then shrank to nothing as $A$ continued to advance. When $B$ then failed to "reappear", observers perceived it as having been "entrained" by $A$ and carried off by it. Readers may experience the entraining cognitive primitive for themselves online

(http://www.smithsrisca.co.uk/EVA-demo3.pptx).

In his most ambitious studies Michotte used three blocks, A, B, and an intermediary I, such that $A$ moved in to launch I, which then moved on to launch $\mathrm{B}$. He found that by varying relative speeds and distances he could control whether an observer saw a single complex operation (A launching $B$ via a non-perpetrating $I)$, or two successive events (A launching I; I launching B). Readers may experience the intermediate perpetrator effect for themselves online

(http://www.smithsrisca.co.uk/EVA-demo4.pptx).

\section{CINEMATOGRAPHIC DECEIT}

The four cognitive primitives described above each support a particular type of visual deception. Thus EVA-demo1.pptx demonstrates how deceitful launching is used in variations of the faked stage punch or recoiling cannon, EVA-demo2.pptx demonstrates deceitful screen effect in stage stabbings and the Frame 313 retouching of the JFK assassination film, and EVA-demo3.pptx shows deceitful entraining in the well-known "shell game". However, the situation is slightly more complicated with the intermediate perpetrator effect because both the single-actor and double-actor versions can be faked. Thus EVA-demo4.pptx shows both (a) deceitful single-actor perpetration in the familiar stage gunshot (bang-splash, but no bullet), and (b) possibly deceitful double-actor perpetration in the publicly available footage of the collapse of the South Tower, World Trade Center, on $11^{\text {th }}$ September 2001.
The first three types of cinematographic deceit require little additional discussion, in that they clearly demonstrate not just that early processing can be fooled but also that the resulting conscious experience remains fooled. Our high-level cognitive processes, in other words, evolved to believe whatever the cognitive primitives are telling them, and are not easily disabused of that belief. The fourth type of deceit is therefore intimately involved in a more general cognitive ability, namely that of attributing motives to the players in the outside world. This type of cognition has tremendous survival value because it tells us who to associate with and how to behave when strange and potentially life-threatening things happen. The ability to spot the perpetrators in the world is central to this, and our judgements in this respect not only become our personal narrative, but also are duly stored away for future reference as our life history. In short, the detection of perpetration - the intentional doing of something by someone, but not necessarily in person - may fairly be regarded as the highest form of cognition.

There are, of course, still many secrets to be discovered in Plato's cave-cinema. We urgently need better definitions of what happens within each processing stage, of what is passed between the stages, and of the methods of content-addressable memory retrieval at point of arrival. We also have little idea of how low-level approach-avoidance signals get to be experienced as the qualia of pleasure or pain higher up. And, like Plato's incarcerated cinemagoers, we shall remain in the dark until these mysteries are resolved.

\section{REFERENCES}

Meinong, A. (1902) Über Annahmen. Barth, Leipzig.

Michotte, A. (1963) The Perception of Causality. Methuen, London.

Plato (380BCE) The Republic. Internet Classics. http://classics.mit.edu/Plato/republic.html (retrieved 5 March 2018).

Smith, D. J. (1993) The Psychology of Effective College Governance: Part 2 - the cognitive skills. Journal of Further and Higher Education, 17:77-85. 